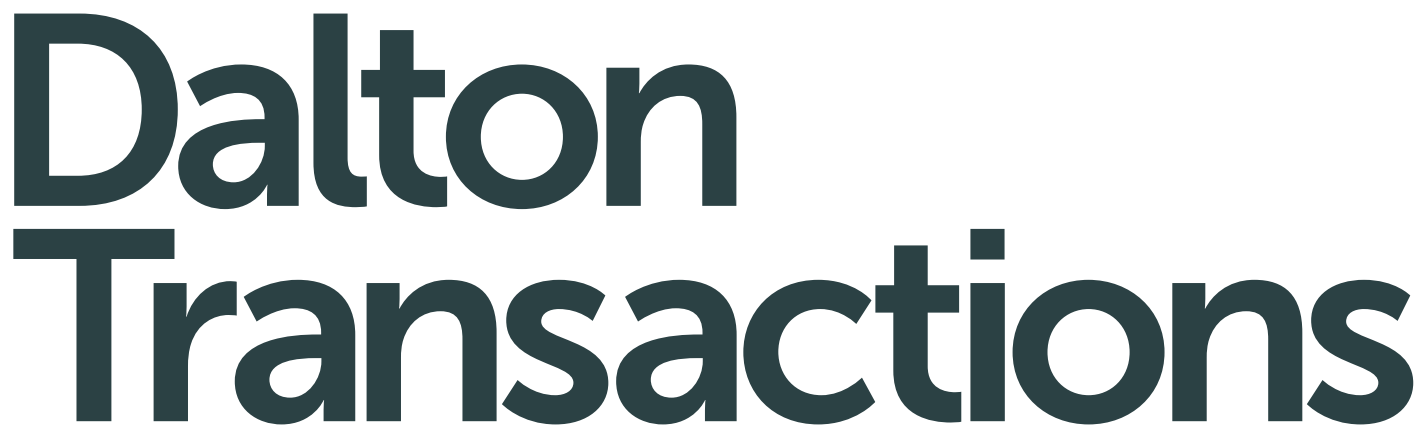

An international journal of inorganic chemistry

www.rsc.org/dalton

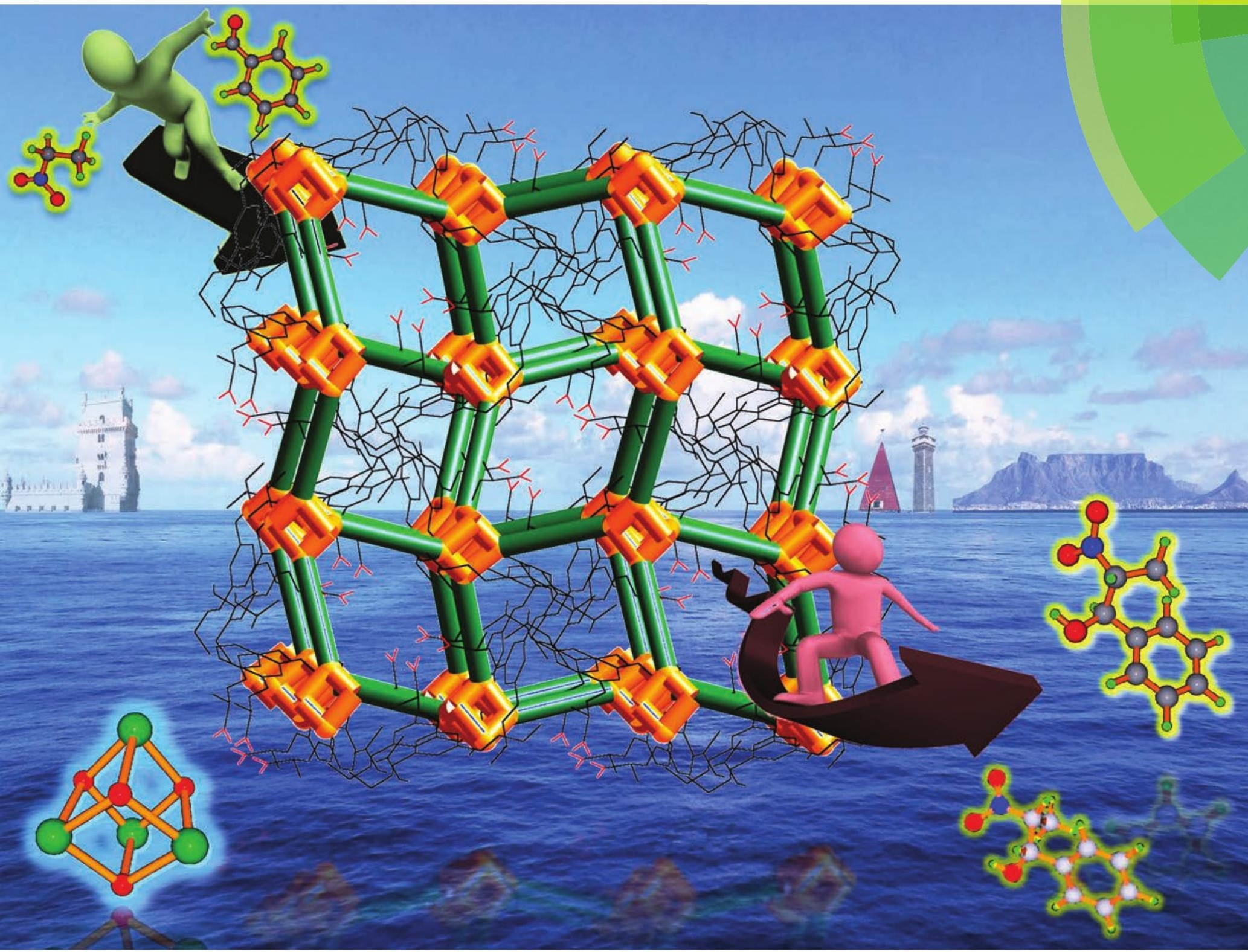

ISSN $1477-9226$

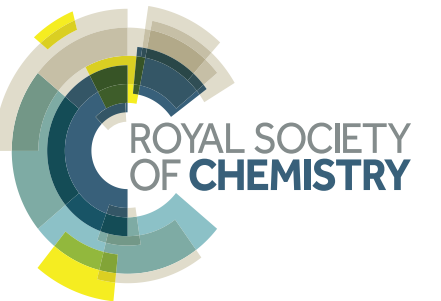

Anirban Karmakar, Clive L. Oliver et al.

The synthesis, structure, topology and catalytic application of a novel

cubane-based copper(II) metal-organic framework derived from a flexible amido tripodal acid 


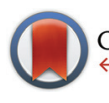

CrossMark $\leftarrow$ click for updates

Cite this: Dalton Trans., 2015, 44 10156

Received 7th October 2014 Accepted 22nd January 2015 DOI: $10.1039 / c 4 d t 03087 \mathrm{~g}$ www.rsc.org/dalton

\section{The synthesis, structure, topology and catalytic application of a novel cubane-based copper(II) metal-organic framework derived from a flexible amido tripodal acid $\uparrow$}

\begin{abstract}
Anirban Karmakar, ${ }^{\star a, b}$ Clive L. Oliver, ${ }^{* c}$ Somnath Roy ${ }^{\mathrm{b}}$ and Lars Öhrström ${ }^{a}$
A novel chiral metal-organic framework, $\left[\mathrm{Cu}_{4}(\mathrm{HL})_{2}\left(\mathrm{H}_{2} \mathrm{O}\right)_{4}(\mathrm{MeO})_{4}\right]_{n}(1)$, has been successfully synthesized from a tripodal flexible ligand (2S,2'S,2"S)-2,2',2"-(benzenetricarbonyltris(azanediyl))tripropanoic acid $\left(\mathrm{H}_{3} \mathrm{~L}\right)$. Compound 1 was characterized by IR and X-ray powder diffraction analysis. The structure was determined by $X$-ray single crystal diffraction analysis revealing that 1 possesses a 3D network, featuring a tetranuclear cubane-type secondary building block $\left[\mathrm{Cu}_{4}(\mathrm{MeO})_{4}\right]^{4+}$, formed via the connection of four metal ions to four methoxide ions. These secondary building blocks are linked by four different $\mathrm{HL}^{2-}$ ligands to construct a porous three dimensional framework of the dia topology with one-dimensional channels. Compound 1 also acts as a heterogeneous catalyst for the diastereoselective nitroaldol (Henry) reaction, providing high yields (up to 91\%) and good diastereoselectivities under ambient conditions. This catalyst can be recycled without significant loss of activity.
\end{abstract}

\section{Introduction}

Porous metal-organic frameworks (MOFs) ${ }^{1}$ have attracted much interest in recent years due to their intriguing topologies $^{1 j-m}$ along with potential applications in the fields of gas sorption, ${ }^{2}$ magnetism, ${ }^{3}$ nonlinear optics, ${ }^{4}$ chiral separation ${ }^{5}$ and catalysis. ${ }^{6}$ The judicious selection of appropriate linkers can give rise to the desired pore shape and size upon coordination and consequently contribute significantly to the structural design of MOFs, as well as their properties. Highly symmetrical multitopic ligands with dicarboxylate, ${ }^{7}$ tricarboxylate $^{8}$ and tetracarboxylate ${ }^{9}$ functionalities may bridge mono- or multi-nuclear metal nodes, leading to stable MOFs with permanent porosity ${ }_{10}{ }^{10}$ while flexible ligands with additional functional groups may adopt more versatile conformations and coordination modes according to the geometric requirements of different metal ions, which may lead to unpredictable, yet interesting topologies and properties. However, only a few

\footnotetext{
${ }^{a}$ Chemical and Biological Engineering, Physical Chemistry, Chalmers University of Technology, SE-412 96, Gothenburg, Sweden. E-mail: ohrstrom@chalmers.se

${ }^{b}$ Centro de Quimica Estrutural, Instituto Superior Técnico, Universidade de Lisboa, Av. Rovisco Pais, 1049-001 Lisbon, Portugal. E-mail: anirbanchem@gmail.com ${ }^{c}$ Centre for Supramolecular Chemistry Research, Department of Chemistry, University of Cape Town, Rondebosch, Cape Town 7701, South Africa.

E-mail: Clive.Oliver@uct.ac.za

$\dagger$ Electronic supplementary information (ESI) available. CCDC 1024691. For ESI and crystallographic data in CIF or other electronic format see DOI: 10.1039/ c4dt03087g
}

examples with flexible di- and tripodal ligands have been reported and the investigation of metal-organic frameworks based on them is still a great challenge. ${ }^{11}$

The Henry or nitroaldol reaction is known as one of the most powerful and atom-economical reactions for $\mathrm{C}-\mathrm{C}$ bond formation with various functionalized structural motifs. ${ }^{12}$ Usually this reaction is performed with homogeneous basic catalysts, such as alkali metal hydroxides, alkoxides or amines, with a rather good efficiency. ${ }^{13}$ The development of new catalysts and procedures for the Henry reaction has been constantly elaborated in view of the reduction of toxic by-products and the increase of yield and diastereoselectivity. In the last two decades many other asymmetric catalysts have been developed to convert aldehydes or $\alpha$-keto esters into the corresponding nitroalkanol with good enantio- and diastereoselectivity. ${ }^{14}$ Even though high yields were achieved with reactions performed with homogeneous catalysts, the achievement of a high stereoselectivity is still challenging, and only a scant number of examples are known ${ }^{15}$ using heterogeneous catalysts. Some copper and zinc-containing metal organic frameworks ${ }^{16}$ have been reported, which actively catalyze the nitroaldol reaction. However, there is still a demand to develop new types of catalysts based on cheap and environmentally tolerable metal organic frameworks that could be easily recyclable (hence forming a heterogeneous system) and show a high efficiency under mild conditions.

Recently, a systematic investigation on a series of flexible di- and tripodal acid ligands containing various amino acid 


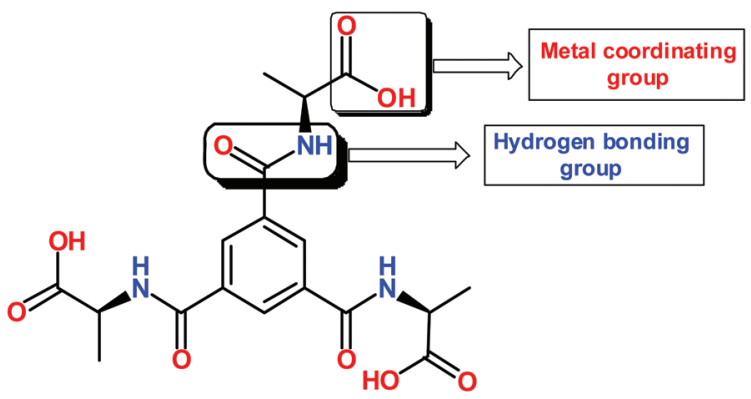

(2S,2'S,2"S)-2,2',2"-(benzenetricarbonyltris(azanediyl))tripropanoic acid $\left(\mathrm{H}_{3} \mathrm{~L}\right)$

Scheme 1

groups has been reported by us, which led to interesting hydrogen bonding networks. ${ }^{17}$ We have extended our study by synthesizing a higher dimensional motif (metal organic framework) with an easily accessible tripodal linker. Thus, two main objectives of this study were as follow: (i) to synthesize a $\mathrm{Cu}(\mathrm{II})-\mathrm{MOF}$ using a tripodal acid linker; (ii) to apply the synthesized framework as a heterogeneous catalyst in the nitroaldol combination of nitroethane with various aldehydes. In that context, we chose $\left(2 S, 2^{\prime} S, 2^{\prime \prime} S\right)-2,2^{\prime}, 2^{\prime \prime}$-(benzenetricarbonyltris(azanediyl))tripropanoic acid $\left(\mathrm{H}_{3} \mathrm{~L}\right)$ [Scheme 1] which is more flexible than benzene tricarboxylic acid as the carboxylic acid groups are reasonably free to rotate whilst the amide functional groups may potentially be involved in hydrogen bonding for further stabilization of the resulting structure.

Hence, we report herein the synthesis and characterization of a new chiral copper(II) metal organic framework, prepared under hydrothermal conditions, using a flexible tripodal acid linker $\mathrm{H}_{3} \mathrm{~L} \quad\left[\left(2 S, 2^{\prime} S, 2^{\prime \prime} S\right)-2,2^{\prime}, 2^{\prime \prime}\right.$-(benzenetricarbonyltris(azanediyl))tripropanoic acid]. The structural features of the obtained $\mathrm{Cu}-\mathrm{MOF}\left[\mathrm{Cu}_{4}(\mathrm{HL})_{2}\left(\mathrm{H}_{2} \mathrm{O}\right)_{4}(\mathrm{MeO})_{4}\right]_{n}$ (1) could be established by single crystal $\mathrm{X}$-ray diffraction analysis which revealed a cubane-type metal-oxygen cluster not yet observed for a metal-organic framework. The structure was also subjected to a topological study.

The catalytic performance of this framework as a heterogeneous catalyst, in terms of activity, heterogeneity, and recyclability, was successfully tested for the nitroaldol (Henry) reaction of nitroethane with various aldehydes in a methanolic medium.

\section{Results and discussion}

\section{2a. Syntheses and characterization}

The hydrothermal reaction of $\mathrm{H}_{3} \mathrm{~L}$ with copper(II) nitrate trihydrate in the presence of dimethyl formamide and methanol leads to the formation of $\left[\mathrm{Cu}_{4}(\mathrm{HL})_{2}\left(\mathrm{H}_{2} \mathrm{O}\right)_{4}(\mathrm{MeO})_{4}\right]_{n} \quad$ (1) $\left[\mathrm{L}=\left(2 S, 2^{\prime} S, 2^{\prime \prime} S\right)-2,2^{\prime}, 2^{\prime \prime}\right.$-(benzenetricarbonyltris(azanediyl)) tripropanoate].

In the IR spectra, the characteristic strong bands of the coordinated carboxylate groups of 1 appear at $1530 \mathrm{~cm}^{-1}$ and $1360 \mathrm{~cm}^{-1}$ for the asymmetric and the symmetric stretching, respectively. $\mathrm{C}-\mathrm{O}$ stretching of the coordinated carboxylate group is observed at $1270 \mathrm{~cm}^{-1}$. A strong band at $1637 \mathrm{~cm}^{-1}$ is due to $\nu(\mathrm{CO})$ of the uncoordinated carboxylic acid, ${ }^{18}$ whereas $\nu(\mathrm{OH})$ of water molecules is in the $3303 \mathrm{~cm}^{-1}$ region. The band at $1580 \mathrm{~cm}^{-1}$ is attributed to $\mathrm{C}=\mathrm{O}$ stretching vibration of the amide group. Metal organic framework 1 was also characterized by single crystal X-ray diffraction and powder X-ray diffraction analysis.

Thermogravimetric analysis was also performed on framework 1 (Fig. S5, ESI $\dagger$ ). Framework 1 shows a weight loss of $5.30 \%$ between 71 and $141{ }^{\circ} \mathrm{C}$, corresponding to the loss of two molecules of water (calcd: 5.60\%). Upon further heating, framework 1 exhibits a weight loss of $9.40 \%$ in the $180-239^{\circ} \mathrm{C}$ temperature range, which accounts for the total removal of two coordinated methoxy molecules (calcd: $9.60 \%$ ). The remaining material then starts to decompose from $241^{\circ} \mathrm{C}$ until $492^{\circ} \mathrm{C}$.

\section{2b. Crystal structure analysis}

Single-crystal X-ray diffraction studies reveal that $\left[\mathrm{Cu}_{4}(\mathrm{HL})_{2}{ }^{-}\right.$ $\left.\left(\mathrm{H}_{2} \mathrm{O}\right)_{4}(\mathrm{MeO})_{4}\right]_{n}$ (1) crystallizes in a chiral space group (the tetragonal space group $P 4_{3} 2_{1} 2$ ), which is expected due to the chirality of the ligand. The asymmetric unit contains two copper(II) ions, one $\mathrm{HL}^{2-}$ ligand, two water molecules and two methoxide ions (Fig. 1). The formulation of this framework is based on the typical Jahn-Teller distortion of $\mathrm{Cu}$ (II) (vide infra) and the $\mathrm{Cu}-\mathrm{O}$ distances $[1.945(4)-1.951(4) \AA]$, which correspond closer to those observed for $\mathrm{Cu}-\mathrm{OMe}(1.94 \AA)$ than for $\mathrm{Cu}-\mathrm{O}(\mathrm{H}) \mathrm{Me}(1.99 \AA) .{ }^{19 a}$ In addition, the EPR results below confirm that the copper ions are in the $2+$ oxidation state.

Both copper(II) centres have square pyramidal geometry $\left(\tau_{5}=0.06\right.$ for $\mathrm{Cu} 1$ and $\tau_{5}=0.04$ for $\mathrm{Cu} 2$ ) and the coordination sphere of each copper(II) center is occupied by one carboxylate oxygen atom of a $\mathrm{HL}^{2-}$ unit [Cu1-O2, 1.969(4) А; Cu2-O5, 1.977(4) §] , three methoxide O-atoms and a water molecule. The carboxylate oxygen, two methoxide O-atoms and the water molecule occupy the equatorial sites and the axial site coordinated by the remaining methoxide ion. As expected and

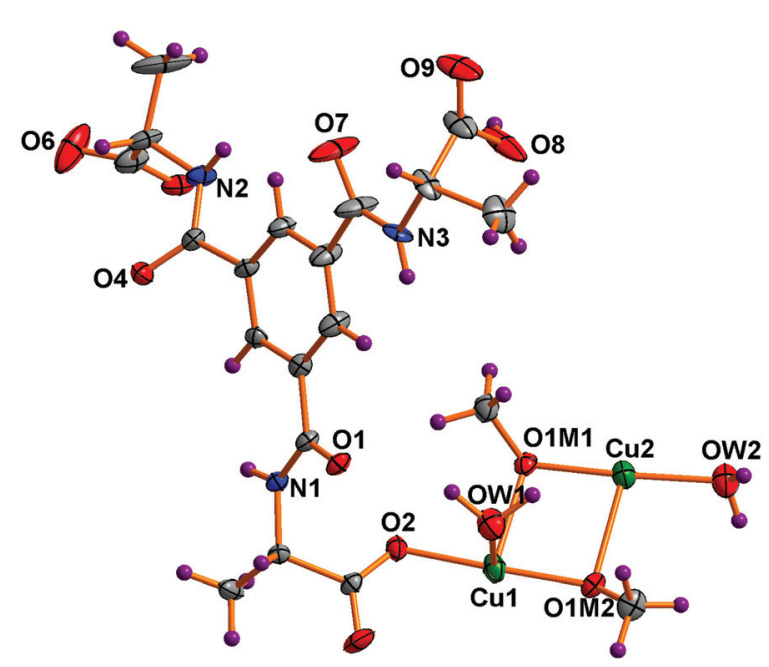

Fig. 1 Asymmetric unit of 1 with the partial atom labeling scheme. 


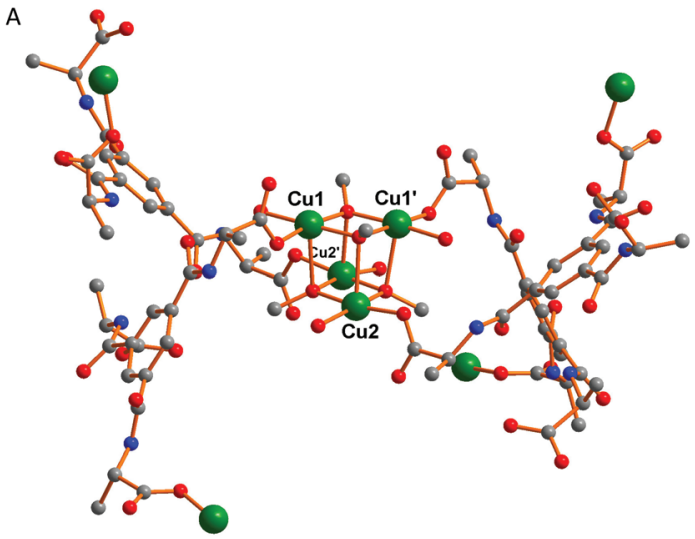

B

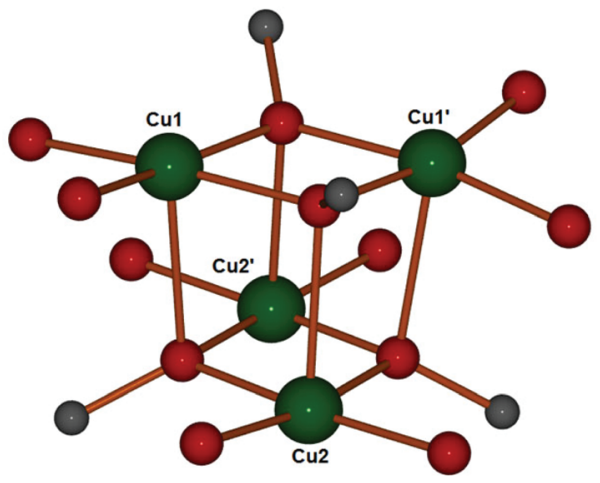

Fig. 2 (A) Coordination scheme around the tetranuclear copper(II) core in 1. (B) Structure of the tetranuclear cubane-type clusters of the $\left[\mathrm{Cu}_{4}(\mathrm{MeO})_{4}\right]^{4+}$ unit showing the metal coordination spheres.

due to Jahn-Teller distortion ${ }^{19 b-e}$ the axial $\mathrm{Cu}-\mathrm{O}$ bond distance is slightly longer [Cu1-O1M1, 2.424(4) А; Cu2-O1M2, 2.405(4) $\AA]$ than the equatorial ones. The equatorial $\mathrm{Cu}-\mathrm{O}$ bond lengths vary from 1.945(4) to 2.004(5) A (Table S2†). Selected bond distances and angles of $\mathbf{1}$ are listed in Table S2 (ESI $\dagger$ ).

In this framework tetranuclear cubane-type clusters of $\left[\mathrm{Cu}_{4}(\mathrm{MeO})_{4}\right]^{4+}$ (Fig. 2B) serve as secondary building block units (SBUs) and are located about 2-fold rotation axes. In the literature very few copper(II) complexes having methoxobridged $^{20 a-f}$ and oxygen-bridged ${ }^{20 g-j}$ cubane-type tetranuclear clusters are reported, but to our knowledge, no metal-organic frameworks involving any type of oxygen bridge with the same cubane motif as observed for $\mathbf{1}$ have been reported, albeit that it has been observed for discrete clusters. ${ }^{20 d}$

Every tetranuclear cluster is associated with four $\mathrm{HL}^{2-}$ ligands, four molecules of water and four $\mu_{3}$-methoxy ions. The carboxylate groups of ligand $\mathrm{HL}^{2-}$ are associated with the two neighbouring tetranuclear clusters, while the carboxylic acid group remains uncoordinated and orients itself towards the open channels.

The packed view of $\mathbf{1}$ is characterized by open channels along the crystallographic $c$ axis (Fig. 3) with approximate dimensions of $6 \times 7 \AA^{2}$ and a void space of $16.2 \%$ per unit cell according to PLATON. ${ }^{34}$ The structure of $\mathbf{1}$ is also stabilized by hydrogen bonding interactions, three amide hydrogen atoms

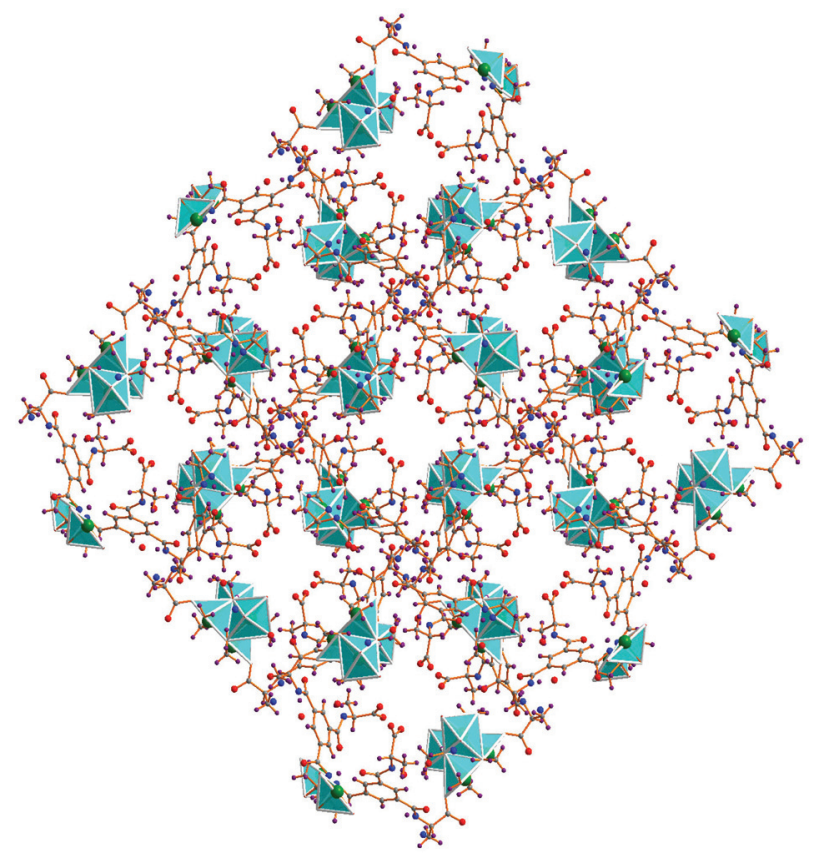

Fig. 3 A representation of the 3D network of 1.

of ligand $\mathrm{HL}^{2-}$ are hydrogen bonded with three amide oxygen atoms of neighboring $\mathrm{HL}^{2-}$ ligands via N1-H1 ‥ O1\#1 2.9581 (2) $\AA, \mathrm{N} 2-\mathrm{H} 2 \cdots \mathrm{O} 7 \# 2$ 2.9302(2) $\AA$ and N3A-H3A $\cdots \mathrm{O} 4 \# 33.0067$ (2) $\AA$, \#1 1/2 - y, 1/2 + x, -1/4 + z; \#2 $y, x, 1-z ; \# 3-1 / 2+y, 1 / 2$ $-x, 1 / 4+z$ interactions. Hydrogen bonding interactions between carboxylate oxygen atoms $\mathrm{O} 2$ and O0AA (as acceptors) and the OW2 hydrogen atoms of water molecules (as bifurcated donors) are also observed [OW2-H1W2 ‥O2\#4 3.1165(2)

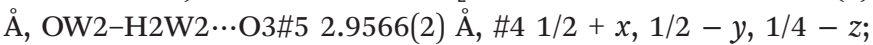
$\# 51-y,-x, 1 / 2-z]$. In addition, intermolecular $\mathrm{C}-\mathrm{H} \cdots \mathrm{O}$ contacts are relevant and help in stabilizing the structure (Table S3, ESI $\dagger$ ).

The topology of $\mathbf{1}$ was determined by considering the $\mathrm{Cu}_{4} \mathrm{O}_{4}$ units as vertices and the ligand as a linear connector in analyzing the network with SYSTRE. ${ }^{21 a, b}$ This operation reveals the ubiquitous diamond or dia topology, the most common of all four connected nets. ${ }^{21 b}$ The structure with an overlaid network is shown in Fig. 4. It is noteworthy that although $\mathbf{1}$ crystallizes in an enantiomorphous space group the dia net is not one of the inherently chiral network topologies (qtz is the most common of these that are four-connected). As observed in the literature the topology of the net is not necessarily chiral even if the space group is chiral. ${ }^{22}$

\section{Catalytic activity of 1 in the Henry reaction}

We have tested the catalytic activity of the copper MOF $\mathbf{1}$ as a solid heterogeneous catalyst in the nitroaldol (or Henry) reaction of nitroethane with various aldehydes. In a typical reaction, a mixture of aldehyde $(0.50 \mathrm{mmol})$, nitroethane 


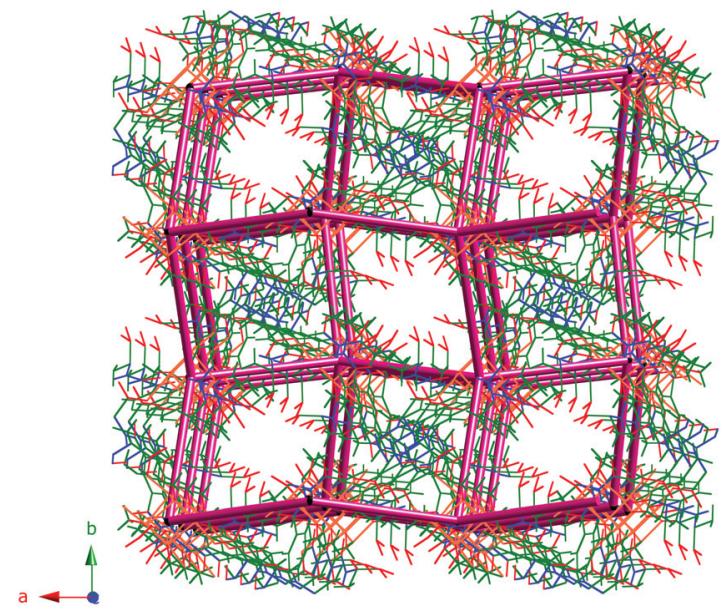

Fig. 4 Structure of compound 1 with the underlying dia topology shown in purple. Solvent water molecules are not shown.

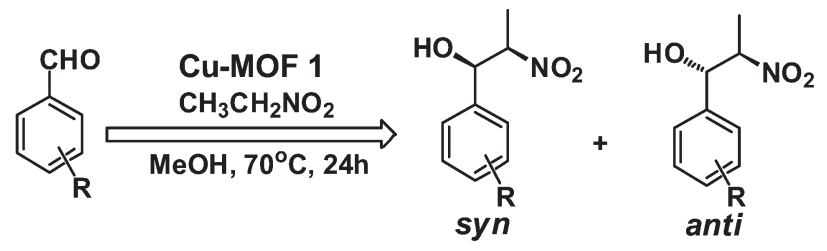

Scheme 2 Nitroaldol (Henry) reaction.

( $2.50 \mathrm{mmol}$ ), $3 \mathrm{~mol} \%$ of Cu-MOF catalyst and methanol contained in a capped glass vessel was stirred at $70{ }^{\circ} \mathrm{C}$ for $24 \mathrm{~h}$. The mixture was then centrifuged to remove the solid catalyst. The evaporation of the solvent gave the crude product which was a mixture of the $\beta$-nitroalkanol diastereoisomers (syn and anti forms, with the predominance of the former) which were analyzed by ${ }^{1} \mathrm{H}$ NMR.

The optimization of the reaction conditions (temperature, reaction time, the amount of catalyst, solvent) was carried out in a model nitroethane-benzaldehyde system with $\mathbf{1}$ as the catalyst (Scheme 2 with typical reaction conditions; Table 1).

When $3 \mathrm{~mol} \%$ of solid complex $\mathbf{1}$ is used as the catalyst at $70{ }^{\circ} \mathrm{C}$, a conversion of $89 \%$ (syn/anti: $75: 25$ ) of benzaldehyde into $\beta$-nitroalkanol is reached (entry 6, Table 1) after $24 \mathrm{~h}$. Upon extending the reaction time to $48 \mathrm{~h}$, the reaction yield increased slightly $(91 \%$, syn/anti: $76: 24)$. The plot of yield versus time for the Henry reaction of benzaldehyde and nitroethane with complex $\mathbf{1}$ is presented in Fig. 5A.

A blank reaction was performed (the absence of any metal source; Table 1, entry 18) using benzaldehyde as the substrate, at $70{ }^{\circ} \mathrm{C}$ and in methanol. No $\beta$-nitroalkanol was detected after a reaction time of $24 \mathrm{~h}$. The nitroaldol reaction also did not take place when using compound $\mathrm{H}_{3} \mathrm{~L}$ instead of catalyst 1 (Table 1, entry 20). We have also checked the reactivity of $\mathrm{Cu}\left(\mathrm{NO}_{3}\right)_{2} \cdot 3 \mathrm{H}_{2} \mathrm{O}$ in methanol medium and the obtained reaction yield was much lower, i.e. ca. $24 \%$ (entry 19, Table 1).
We have also tested the effects of temperature, catalyst amount and solvents. The increase in the amount of catalyst $\mathbf{1}$ from 1.0 to $3.0 \mathrm{~mol} \%$ enhances the product yield from 58 to $89 \%$, but a further increase in the amount of the catalyst leads to a slight decrease of the reaction yield (entries 8-10, Table 1).

To select the most suitable solvent, experiments with various solvents $\left(\mathrm{CH}_{3} \mathrm{CN}\right.$, THF, $\mathrm{MeOH}$ and water) have been carried out with 1 and the results (Table 1, entries 6 and 11-13) indicate that methanol (conversion of $89 \%$ ) is the best polar solvent, whereas the worst one is $\mathrm{CH}_{3} \mathrm{CN}(12 \%$ conversion). In water and THF, yields of $84 \%$ or $45 \%$, respectively, were obtained (Table 1, entries 12 and 13).

Varying the temperature from 20 to $70{ }^{\circ} \mathrm{C}$ improved the yield of $\beta$-nitroalkanol from 5 to $89 \%$ but a further temperature increase had a negative effect (entries 14-17, Table 1). The systems exhibit diastereoselectivity towards the syn isomer, typically leading to syn/anti molar ratios in the $82: 18$ to $78: 22$ range using nitroethane as the substrate. The selectivity in syn and anti products is an important issue in the Henry reaction and efforts have been focused on the development of catalytic diastereo- or enantio-selective processes. ${ }^{23}$ The size of the nitroalkane chain also affects the yield, e.g. with nitropropane the conversion was only $23 \%$ (entry 22 , Table 1 ), whilst with nitroethane or nitromethane conversion values of $89 \%$ or $87 \%$, respectively, were obtained (entries 6 and 21, Table 1).

We also examined the catalytic activity of $\mathbf{1}$ with different types of substituted aromatic and aliphatic aldehydes in the reaction with nitroethane. The results are summarized in Table 2. $p$-Nitrobenzaldehyde produced the maximum yield (95\%), while the lowest yield $(27 \%)$ was obtained for $p$-methoxybenzaldehyde. The yields for two aliphatic aldehydes were good (84-85\%) but lower than that for benzaldehyde.

Competition reactions involving equal molar amounts of $p$-nitrobenzaldehyde and acetaldehyde were conducted to probe whether catalysis occurs primarily on the surface of the MOF or within the pores. If catalysis were occurring to a significant extent within pores, we might well expect the 3-nitrobutan-2-ol product to be formed preferentially over the 2-nitro-1-(4-nitrophenyl)propan-1-ol, since the internal cavities of framework 1 would have selectively adsorbed small molecules (acetaldehyde) over large molecules ( $p$-nitrobenzaldehyde) due to its smaller pore size ( $6 \AA \times 7 \AA$ channels). We have observed that $p$-nitro benzaldehyde produces more yield than acetaldehyde. Also we have used various sizes of different aldehydes but we did not observe any selectivity for a particular aldehyde, the aryl aldehydes bearing electron-withdrawing groups exhibit higher reactivities than those having electrondonating moieties, which may be related to an increase in the electrophilicity of the substrate in the former case. Thus, it may be possible that catalysis occurs mainly on the surface of the MOF and not on the pores of framework 1.

In order to examine the stability of $\mathbf{1}$ in the Henry reaction, it was recycled in four consecutive experiments, and it was observed that its activity remained almost the same (Fig. 5B). FT-IR and powder X-ray diffraction of catalyst 1 performed before and after the reaction indicated that the structure of the 
Table 1 Optimization of the parameters of the Henry nitroaldol reaction between benzaldehyde and nitroethane with 1 as the catalyst ${ }^{a}$

\begin{tabular}{|c|c|c|c|c|c|c|c|c|}
\hline Entry & Catalyst & Time (h) & $\begin{array}{l}\text { Amount of the } \\
\text { catalyst (mol\%) }\end{array}$ & $T\left({ }^{\circ} \mathrm{C}\right)$ & Solvent & Yield $^{b}(\%)$ & $\begin{array}{l}\text { Selectivity }{ }^{c} \\
\text { (syn/anti) }\end{array}$ & $\mathrm{TON}^{d}$ \\
\hline 1 & 1 & 2 & 3.0 & 70 & $\mathrm{MeOH}$ & 40 & $77: 23$ & 13.3 \\
\hline 3 & 1 & 6 & 3.0 & 70 & $\mathrm{MeOH}$ & 65 & $75: 25$ & 21.6 \\
\hline 4 & 1 & 8 & 3.0 & 70 & $\mathrm{MeOH}$ & 72 & $75: 25$ & 24.0 \\
\hline 5 & 1 & 10 & 3.0 & 70 & $\mathrm{MeOH}$ & 78 & $75: 25$ & 26.0 \\
\hline 6 & 1 & 24 & 3.0 & 70 & $\mathrm{MeOH}$ & 89 & $75: 25$ & 29.6 \\
\hline 8 & 1 & 24 & 1.0 & 70 & $\mathrm{MeOH}$ & 58 & $77: 23$ & 58.0 \\
\hline 9 & 1 & 24 & 5.0 & 70 & $\mathrm{MeOH}$ & 79 & $79: 21$ & 15.8 \\
\hline 10 & 1 & 24 & 7.0 & 70 & $\mathrm{MeOH}$ & 81 & $78: 22$ & 11.5 \\
\hline 11 & 1 & 24 & 3.0 & 70 & $\mathrm{CH}_{3} \mathrm{CN}$ & 12 & $79: 21$ & 4.0 \\
\hline 12 & 1 & 24 & 3.0 & 70 & THF & 45 & $80: 20$ & 15.0 \\
\hline 17 & 1 & 24 & 3.0 & 110 & $\mathrm{MeOH}$ & 63 & $69: 31$ & 21.0 \\
\hline 18 & Blank & 24 & - & 70 & $\mathrm{MeOH}$ & - & - & - \\
\hline 19 & $\mathrm{Cu}\left(\mathrm{NO}_{3}\right)_{2} \cdot 3 \mathrm{H}_{2} \mathrm{O}$ & 24 & 3.0 & 70 & $\mathrm{MeOH}$ & 24 & $82: 18$ & 8.0 \\
\hline 20 & $\mathrm{H}_{3} \mathrm{~L}$ & 24 & - & 70 & $\mathrm{MeOH}$ & - & - & - \\
\hline $21^{e}$ & 1 & 24 & 3.0 & 70 & $\mathrm{MeOH}$ & 87 & - & 29.0 \\
\hline $22^{f}$ & 1 & 24 & 3.0 & 70 & $\mathrm{MeOH}$ & 23 & $91: 9$ & 7.7 \\
\hline
\end{tabular}

${ }^{a}$ Reaction conditions: $3.0 \mathrm{~mol} \%$ of catalyst 1 , benzaldehyde $(0.50 \mathrm{mmol})$, nitroethane $(2.50 \mathrm{mmol})$ and methanol $(2 \mathrm{~mL}) .{ }^{b}$ The number of moles of $\beta$-nitroalkanol per mole of the aldehyde $\times 100 .{ }^{c}$ Calculated by ${ }^{1} \mathrm{H}$ NMR. ${ }^{d}$ The number of moles of $\beta$-nitroalkanol per mole of the catalyst $(2 \mathrm{Cu}$ per mole). ${ }^{e}$ Nitromethane was used as the substrate; ${ }^{f}$ Nitropropane was used as the substrate.
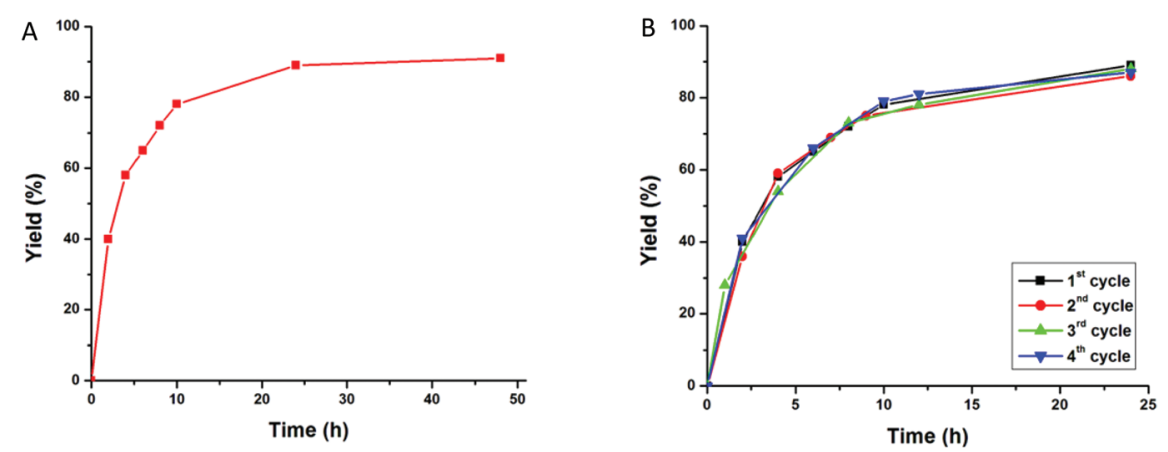

Fig. 5 (A) Plots of $\beta$-nitroalkanol yield vs. time for the Henry reaction of benzaldehyde and nitroethane in the presence of compound 1 as the catalyst. (B) Kinetic profiles in four consecutive reaction cycles employing 1 as the catalyst.

solid was retained (Fig. S1 $\dagger$ ). In addition, the filtered solution, after the separation of the catalyst, was evaporated and the amount of copper was determined, being only $0.012 \%$ of the amount used in the reaction, thus ruling out any significant leaching of the catalyst. This test also indicates the significant stability of framework 1 during the catalytic reaction.

Although there are some reports on coordination polymers ${ }^{16}$ which are catalytically active for this kind of reaction, the yields and selectivity are usually higher for our compound as compared to other metal organic frameworks. Recently,
Chuan-De $\mathrm{Wu}$ et al. reported that a 3D porous metal-organic framework constructed from two kinds of pyridine carboxylates and copper(II) ions, in the reaction of 4-nitrobenzaldehyde and nitroethane, leads to an overall yield of only $78 \%$ after $36 \mathrm{~h}$ reaction time (in our case $95 \%$ in $24 \mathrm{~h}$ ). ${ }^{16 c}$ Moreover, our catalyst 1 exhibits a marked selectivity towards the syn diastereoisomer (Table 2, syn: anti of 78:22) which was not reported in other cases. In comparison with other reported heterogeneous catalysts for the Henry reaction, our catalyst has the advantages of being relatively cheap and easy-toprepare. 
Table 2 Henry reaction of various aldehydes and nitroethane with catalyst $1^{a}$

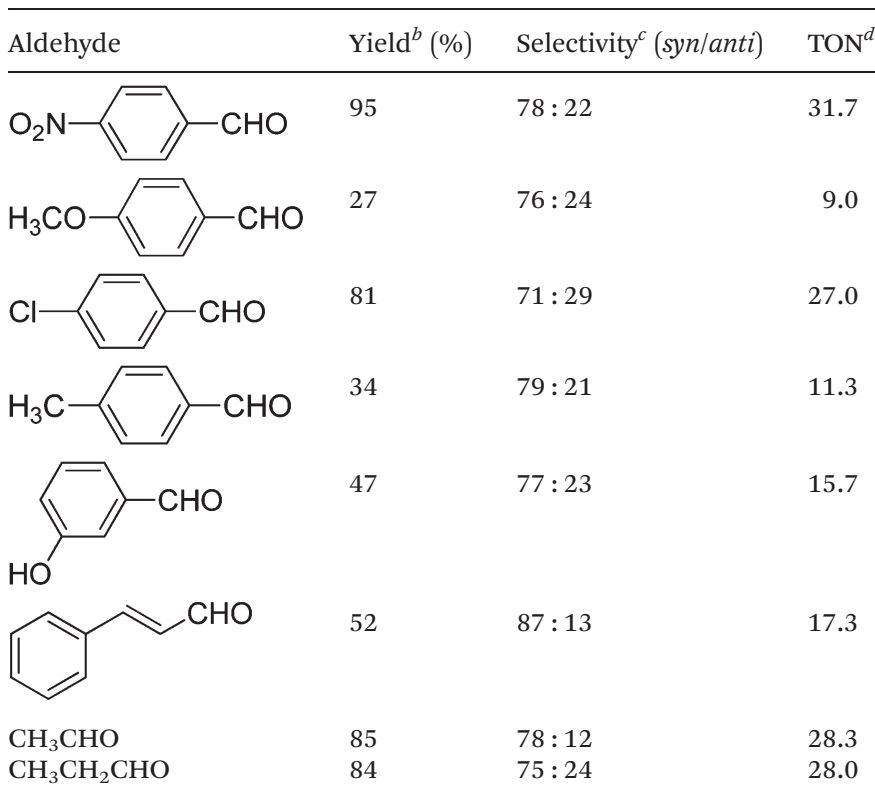

${ }^{a}$ Reaction conditions: $3.0 \mathrm{~mol} \%$ of catalyst 1 , aldehyde $(0.50 \mathrm{mmol})$, nitroethane $(2.5 \mathrm{mmol})$ and methanol $(2 \mathrm{~mL}) .{ }^{b}$ The number of moles of $\beta$-nitroalkanol per mole of the aldehyde $\times 100$. ${ }^{c}$ Calculated by ${ }^{1} \mathrm{H}$ NMR. ${ }^{d}$ The number of moles of $\beta$-nitroalkanol per mole of the catalyst.

\section{EPR analysis}

The EPR spectrum of 1 was recorded in the solid state, Fig. 6(a), at room temperature and (b) at $77 \mathrm{~K}$. The X-band EPR spectrum of 1 depicts a broad band centred at $g=2.15(3171 \mathrm{G}$ for $\nu=9.526 \mathrm{GHz}$ ) which corresponds to the transition $\Delta M_{\mathrm{S}}= \pm 1$. No clearly detectable zero field splitting or half-field signals were observed. The frozen solution spectrum, Fig. 6(b), shows a band centred at $g=2.14$ which also corresponds to the transition $\Delta M_{\mathrm{S}}= \pm 1$. By simulation of the spectra, the following $g$ values were obtained: $g_{1}=2.05, g_{2}=2.17$ and $g_{3}=2.23$.

The geometric parameter $G$, which is a measure of the exchange interaction between the copper centres in the poly- crystalline compound, is calculated using the equation: for rhombic spectra $G=\left(g_{3}-2.003\right) /\left(g_{\perp}-2.003\right)$, where $g_{\perp}=\left(g_{1}+\right.$ $\left.g_{2}\right) / 2$. If $G<4.0$, a considerable exchange interaction is indicated in the solid complexes. ${ }^{24}$ The $G$ value for compound 1 in the polycrystalline state at $77 \mathrm{~K}$ is 2.12 . For complexes of this type, the parameter $R$ can be indicative of the predominance of the $\mathrm{d}_{z}{ }^{2}$ or $\mathrm{d}_{x^{2}-y^{2}}$ orbital in the ground state, where $R=\left(g_{z}-g_{y}\right)$ / $\left(g_{y}-g_{x}\right)$. If $R>1$, the greater contribution to the ground state arises from the $\mathrm{d}_{z}{ }^{2}$ orbital and the structure is closer to a trigonal bipyramid than to a square pyramid. Instead, if $R<1$, a greater contribution to the ground state arises from the $\mathrm{d}_{x^{2}-y^{2}}$ orbital and the structure is closer to a square pyramid than to a trigonal bipyramid. In the present case, $R=0.5$, being compatible with the X-ray diffraction data. The solution spectrum could not be obtained due to the insolubility of the framework 1 in common organic solvents. This result unequivocally confirms the oxidation state as $\mathrm{Cu}$ (II) as inferred in section $2 \mathrm{~b}$.

\section{Conclusion}

We successfully isolated a copper(II) metal organic framework derived from a tripodal flexible ligand $\left(2 S, 2^{\prime} S, 2^{\prime \prime} S\right)-2,2^{\prime}, 2^{\prime \prime}$-(benzenetricarbonyltris(azanediyl))tripropanoic acid $\left(\mathrm{H}_{3} \mathrm{~L}\right)$ under hydrothermal conditions. The single-crystal X-ray diffraction experiment revealed that this framework consists of tetranuclear cubane-type clusters of $\left[\mathrm{Cu}_{4}(\mathrm{MeO})_{4}\right]^{4+}$ acting as secondary building blocks. The tetranuclear cubane of copper(II) is formed via the connection of four metal ions by four $\mu^{3}$ bridged methoxide ions. This metal-oxygen motif, although found for discrete metal-clusters, has not been observed as part of a metal-organic framework hitherto. The framework has one dimensional channels along the $c$ axis with approximate dimensions of $6 \times 7 \AA^{2}$ and a void space of $16.2 \%$ per unit cell volume.

Framework 1 effectively catalyzes the Henry reaction of nitroethane with various aldehydes producing the corresponding $\beta$-nitroalkanols in high yields with a significant stereoselectivity towards the syn diastereomer. We have also proved the stability and recyclability of the catalysts. The syn/ anti ratio of the nitroaldol products depends on various factors
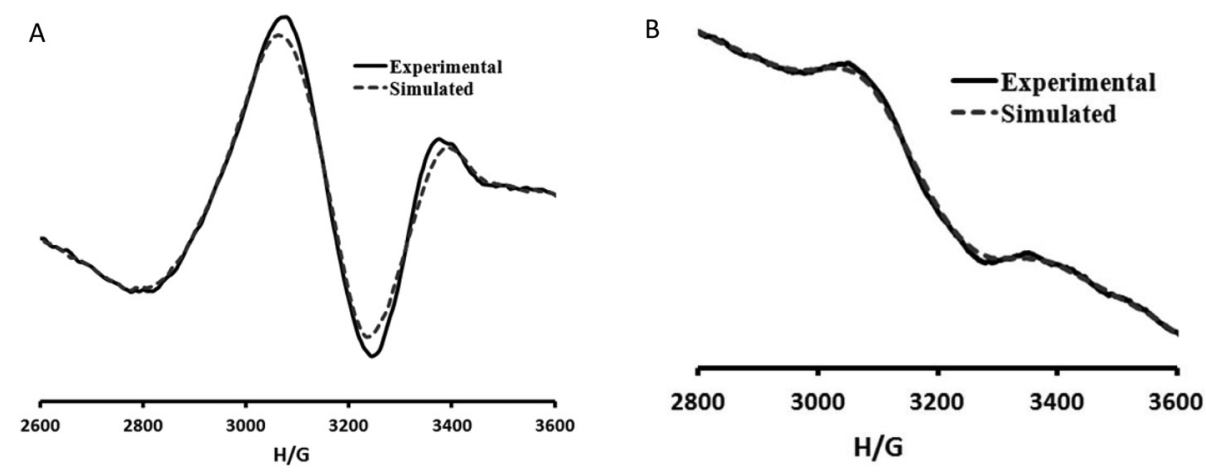

Fig. 6 First derivative EPR spectra of 1 at room temperature (a) and at $77 \mathrm{~K}$ (b). 
such as the amount of the catalyst, the electrophilicity of the substrates and the reaction conditions.

The above observations provide further evidence that simple $\mathrm{Cu}$ (II) complexes can be utilized as effective heterogeneous catalysts in the important types of reactions in this study. Further explorations of the use of this catalyst family in other organic transformations, as well as mechanistic investigations, are ongoing.

\section{Experimental}

All the chemicals were obtained from commercial sources and used as received. $\left(2 S, 2^{\prime} S, 2^{\prime \prime} S\right)-2,2^{\prime}, 2^{\prime \prime}$-(Benzenetricarbonyltris(azanediyl))tripropanoic acid $\left(\mathrm{H}_{3} \mathrm{~L}\right)$ was prepared according to ref. 17 . The infrared spectra $\left(4000-400 \mathrm{~cm}^{-1}\right)$ were recorded on a Bruker IFS-125 spectrometer using $\mathrm{KBr}$ pellets; abbreviations: $\mathrm{s}=$ strong, $\mathrm{m}=$ medium, $\mathrm{w}=$ weak, $\mathrm{bs}=$ broad and strong, $\mathrm{mb}=$ medium and broad. Powder X-ray diffraction (PXRD) was conducted on a D8 Advance Bruker AXS (Bragg Brentano geometry) theta-2theta diffractometer, with copper radiation $(\mathrm{Cu} \mathrm{K \alpha}, \lambda=1.5406 \AA)$ and a secondary monochromator, operated at $40 \mathrm{kV}$ and $40 \mathrm{~mA}$. The flat plate configuration was used and the typical data collection range was between $5^{\circ}$ and $35^{\circ} 2 \theta$. Thermogravimetric analysis was carried out with a Perkin-Elmer Instrument system (STA6000) at a heating rate of $10{ }^{\circ} \mathrm{C} \mathrm{min}^{-1}$ under a dinitrogen atmosphere, in the range of room temperature to $c a .600{ }^{\circ} \mathrm{C}$. The X-band EPR spectra were recorded either at room temperature (RT) or at liquid nitrogen (LN) temperature $(77 \mathrm{~K})$ on a Bruker ESP 300E spectrometer. The ESP 300E spectrometer was operated at $\sim 9.51 \mathrm{GHz}$ with a frequency modulation of $100 \mathrm{kHz}$. While keeping the resolution either at 2048 points or at 4096 points, the microwave power was adjusted to $20 \mathrm{~dB}$ attenuations and the receiver gain was set to either $3.0 \times 10^{5}$ or $4.0 \times 10^{5}$. To improve the signal to noise ratio, 10 scans of each sample were accumulated. The spectral acquisition parameters were constant for each experiment. All measurements were performed using $3 \mathrm{~mm}$ quartz tubes (Wilmad 707-SQ-250M). The EPR spectra were simulated using an EPR simulation program. $^{25}$

\section{6a. Synthesis of 1}

A mixture of $\mathrm{H}_{3} \mathrm{~L}(42 \mathrm{mg}, 0.1 \mathrm{mmol})$ and $\mathrm{Cu}\left(\mathrm{NO}_{3}\right)_{2} \cdot 3 \mathrm{H}_{2} \mathrm{O}$ (24 mg, $0.1 \mathrm{mmol}$ ) was dissolved in $4 \mathrm{~mL}$ of $\mathrm{MeOH}-\mathrm{DMF}$ $(1: 0.1 \mathrm{v} / \mathrm{v})$ and placed in a capped glass vessel. Then $0.1 \mathrm{ml}$ of 1 (M) $\mathrm{KOH}$ is added into it and mixed thoroughly, a blue precipitate appeared immediately. The precipitate was dissolved by adding $0.5 \mathrm{ml}$ of $\mathrm{NH}_{4} \mathrm{OH}$ drop-wise until the solution turned deep blue. The resulting mixture was sealed in an $8 \mathrm{~mL}$ glass vessel and heated at $80{ }^{\circ} \mathrm{C}$ for $48 \mathrm{~h}$. After cooling to room temperature the reaction mixture was kept for slow evaporation. After 7 days deep blue block crystals appeared. The yield was $34 \%$ (based on $\mathrm{Cu}$ ), which was calculated based on the crystalline material obtained. A lower reaction yield of $\mathrm{Cu}$ (II) frameworks was also observed in some previously reported studies. ${ }^{26}$ FT-IR (KBr, cm ${ }^{-1}$ ): 3303 (bs), 1637 (s), 1530 (s), 1450 (w), 1407 (m), 1360 (s), $1270(\mathrm{w}), 1090(\mathrm{w}), 724$ (s).

\section{6b. Procedure for the nitroaldol (Henry) reaction catalyzed by 1}

In a typical reaction, a mixture of aldehyde $(0.50 \mathrm{mmol})$, nitroethane $(2.50 \mathrm{mmol}$ ) and catalyst 1 (9.70 $\mathrm{mg}, 3 \mathrm{~mol} \%)$ was taken in a capped glass vessel, and then $2.0 \mathrm{~mL}$ of methanol were added into it. The mixture was heated at $70^{\circ} \mathrm{C}$ for $24 \mathrm{~h}$, and subsequently quenched by centrifugation and filtration at room temperature. The filtrate was extracted with dichloromethane. The organic extracts were collected over anhydrous sodium sulfate; subsequent evaporation of the solvent gave the crude product. The product was dissolved in DMSO- $\mathrm{d}^{6}$ and analyzed by ${ }^{1} \mathrm{H}$ NMR. The yield of the $\beta$-nitroalkanol product (relative to the aldehyde) was established typically by taking into consideration the relative amounts of these compounds, as given by ${ }^{1} \mathrm{H}$ NMR and previously reported. ${ }^{16 d}$ The ratio between the syn and anti isomers was also determined by ${ }^{1} \mathrm{H}$ NMR spectroscopy. In the ${ }^{1} \mathrm{H}$ NMR spectra, the values of vicinal coupling constants (for the $\beta$-nitroalkanol products) between the $\alpha-\mathrm{N}-\mathrm{C}-\mathrm{H}$ and the $\alpha-\mathrm{O}-\mathrm{C}-\mathrm{H}$ protons help identifying the isomers, being $J=7-9$ or $3.2-4 \mathrm{~Hz}$ for the syn or anti isomers, respectively. ${ }^{27}$ The ${ }^{1} \mathrm{H}$-NMR spectra and the calculation of the yield and selectivity for framework $\mathbf{1}$ in the Henry reaction are presented in ESI (Fig. S4 $\dagger$ ).

In order to perform the recycling experiment, first we washed the used catalyst (separated by centrifugation and filtration of the supernatant solution) with methanol and dried it in air. It was then reused for the nitroaldol reaction as described above.

\section{6c. X-ray crystal structure determination}

A suitable crystal of $\mathbf{1}$ was immersed in cryo-oil, mounted on a Nylon loop, and measured at a temperature of 100(2) K using an Oxford Cryostream 700. The X-ray diffraction data were collected on a Bruker DUO APEX II CCD diffractometer using

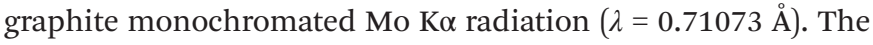
data reduction and cell refinement were performed using SAINT-Plus $^{28}$ and scaled for absorption effects by multi-scan using SADABS. ${ }^{29}$ The space group was determined from systematic absences by XPREP ${ }^{30}$ and confirmed using the program Layer. ${ }^{31}$ The structures were solved by direct methods using SHELXS- $97^{32}$ and subsequently refined by full-matrix least-squares methods, based on $F^{2}$ values against all reflections. ${ }^{33}$ Non-hydrogen atoms were refined with anisotropic displacement parameters, whilst hydrogen atoms were placed geometrically, except for water hydrogen atoms which were placed from difference Fourier maps. Thermal parameters of hydrogen atoms were constrained to $U_{\text {iso }}=1.2 U_{\text {eq }}$ (parent atom). Excess electron density in the channels that could not be modelled was 'cleaned' using the SQUEEZE routine in PLATON. ${ }^{34}$ CCDC 1024691 for compound 1 contains the supplementary crystallographic data for this paper. 


\section{Acknowledgements}

AK expresses his gratitude to the Fundação para a Ciência e a Tecnologia for post-doctoral fellowships (Ref. No. SFRH/BPD/ 76192/2011), LÖ and CLO thank the Swedish Research Links program for Southern Africa, LÖ is also grateful for funding from the Swedish Science Council and Chalmers Tekniska Högskola and CLO thanks the National Research Foundation of South Africa for funding.

\section{References}

1 (a) S. Kitagawa, R. Kitaura and S. Noro, Angew. Chem., Int. Ed., 2004, 43, 2334-2375; (b) S. R. Batten and R. Robson, Angew. Chem., Int. Ed., 1998, 37, 1460-1494; (c) M. Eddaoudi, D. B. Moler, H. Li, B. Chen, T. M. Reineke, M. O'Keeffe and O. M. Yaghi, Acc. Chem. Res., 2001, 34, 319-330; (d) B. Moulton and M. J. Zaworotko, Chem. Rev., 2001, 101, 1629-1658; (e) O. R. Evans and W. Lin, Acc. Chem. Res., 2002, 35, 511-522; (f) A. J. Blake, N. R. Champness, P. Hubberstey, W.-S. Li, M. A. Withersby and M. Schröder, Coord. Chem. Rev., 1999, 183, 117-138; (g) A. Karmakar and I. Goldberg, CrystEngComm, 2011, 13, 350-366; (h) A. Karmakar and I. Goldberg, CrystEngComm, 2011, 13, 339-349; (i) S. R. Batten, N. R. Champness, X.-M. Chen, J. Garcia-Martinez, S. Kitagawa, L. Öhrström, M. O'Keeffe, M. Paik Suh and J. Reedijk, Pure Appl. Chem., 2013, 85, 1715-1724; (j) M. O'Keeffe, M. A. Peskov, S. Ramsden and O. M. Yaghi, Acc. Chem. Res., 2008, 41, 1782-1789; (k) L. Öhrström, in Encyclopedia of supramolecular chemistry, Supramolecular materials chemistry, ed. L. Barbour, Wiley, Chichester, UK, 2012, vol. 6, pp. 3057-3072; (l) N. W. Ockwig, O. Delagado-Friedrichs, M. O'Keeffe and O. M. Yaghi, J. Am. Chem. Soc., 2005, 38, 176-182; (m) V. A. Blatov, L. Carlucci, G. Ciani and D. M. Proserpio, CrystEngComm, 2004, 6, 377.

2 (a) J. L. C. Rowsell and O. M. Yaghi, Angew. Chem., Int. Ed., 2005, 44, 4670; (b) N. L. Rosi, J. Eckert, M. Eddaoudi, D. T. Vodak, J. Kim, M. O'Keeffe and O. M. Yaghi, Science, 2003, 300, 1127-1129; (c) B. Kesanli, Y. Cui, M. R. Smith, E. W. Bittner, B. C. Bockrath and W. Lin, Angew. Chem., Int. Ed., 2005, 44, 72-75; (d) S. Kitagawa, R. Kitaura and S. Noro, Angew. Chem., Int. Ed., 2004, 43, 2334-2375.

3 (a) M. Kurmoo, Chem. Soc. Rev., 2009, 38, 1353-1379; (b) K. C. Mondal, G. E. Kostakis, Y. Lan, C. E. Anson and A. K. Powell, Inorg. Chem., 2009, 48, 9205.

4 (a) O. R. Evans and W. Lin, Acc. Chem. Res., 2002, 35, 511522; (b) W. B. Lin, Z. Y. Wang and L. Ma, J. Am. Chem. Soc., 1999, 121, 11249-11250; (c) M. D. Allendorf, C. A. Bauer, R. K. Bhakta and R. J. T. Houk, Chem. Soc. Rev., 2009, 38, 1330 .

5 (a) M. Padmanaban, P. Müller, C. Lieder, K. Gedrich, R. Grünker, V. Bon, I. Senkovska, S. Baumgärtner, S. Opelt, S. Paasch, E. Brunner, F. Glorius, E. Klemm and S. Kaskel, Chem. Commun., 2011, 47, 12089-12091; (b) W. Wang,
X. Dong, J. Nan, W. Jin, Z. Hu, Y. Chen and J. Jiang, Chem. Commun., 2012, 48, 7022-7024.

6 (a) A. U. Czaja, N. Trukhan and U. Muller, Chem. Soc. Rev., 2009, 38, 1284; (b) A. Corma, H. Garcia and F. X. Llabres i Xamena, Chem. Rev., 2010, 110, 4606; (c) D. Farrusseng, S. Aguado and C. Pinel, Angew. Chem., Int. Ed., 2009, 48, 7502; (d) J.-Y. Lee, O. K. Fahra, J. Roberts, K. A. Scheidt, S.-B. T. Nguyen and J. T. Hupp, Chem. Soc. Rev., 2009, 38, 1450; (e) A. Karmakar, H. M. Titi and I. Goldberg, Cryst. Growth Des., 2011, 11, 2621-2636.

7 (a) A. Schaate, S. Klingelhoefer, P. Behrens and M. Wiebcke, Cryst. Growth Des., 2008, 8, 3200-3205; (b) S. S. Kaye and J. R. Long, J. Am. Chem. Soc., 2008, 130, 806-807; (c) S. S. Kaye, A. Dailly, O. M. Yaghi and J. R. Long, J. Am. Chem. Soc., 2007, 129, 14176-14177; (d) C.-B. Liu, C.-Y. Sun, L.-P. Jin and S.-Z. Lu, New J. Chem., 2004, 28, 1019-1026; (e) A. L. Grzesiak, F. J. Uribe, N. W. Ockwig, O. M. Yaghi and A. J. Matzger, Angew. Chem., Int. Ed., 2006, 45, 2553-2556; (f) K. Hirai, S. Furukawa, M. Kondo, M. Meilikhov, Y. Sakata, O. Sakata and S. Kitagawa, Chem. Commun., 2012, 48, 6472-6474; (g) S. Bauer, C. Serre, T. Devic, P. Horcajada, J. Marrot, G. Ferey and N. Stock, Inorg. Chem., 2008, 47, 7568-7576.

8 (a) D. Sun, S. Ma, Y. Ke, D. J. Collins and H. Zhou, J. Am. Chem. Soc., 2006, 128, 3896-3897; (b) L. Hou, J.-P. Zhang and X.-M. Chen, Cryst. Growth Des., 2009, 9, 2415-2419; (c) S. R. Caskey, A. G. Wong-Foy and A. J. Matzger, Inorg. Chem., 2008, 47, 7751-7756; (d) B. Chen, M. Eddaoudi, S. T. Hyde, M. O'Keeffe and O. M. Yaghi, Science, 2001, 291, 1021-1023; (e) L. Hou, J.-P. Zhang, X.-M. Chen and S. Weng Ng, Chem. Commun., 2008, 4019-4021; $(f)$ D. Sun, Y. Ke, T. M. Mattox, S. Parkin and H. C. Zhou, Inorg. Chem., 2006, 45, 7566-7568.

9 (a) Y. Liu, J. F. Eubank, A. J. Cairns, J. Eckert, V. C. Kravtsov, R. Luebke and M. Eddaoudi, Angew. Chem., Int. Ed., 2007, 46, 3278-3283; (b) X. Lin, J. Jia, X. Zhao, K. M. Thomas, A. J. Blake, G. S. Walker, N. R. Champness, P. Hubberstey and M. Schröder, Angew. Chem., Int. Ed., 2006, 45, 7358-7364; (c) X. Lin, I. Telepeni, A. J. Blake, A. Dailly, C. M. Brown, J. M. Simmons, M. Zoppi, G. S. Walker, K. M. Thomas, T. J. Mays, P. Hubberstey, N. R. Champness and M. Schröder, J. Am. Chem. Soc., 2009, 131, 2159-2171; (d) K. L. Mulfort, O. K. Farha, C. L. Stern, A. A. Sarjeant and J. T. Hupp, J. Am. Chem. Soc., 2009, 131, 3866-3868; (e) O. K. Farha, K. L. Mulfort and J. T. Hupp, Inorg. Chem., 2008, 47, 10223-10225.

10 (a) B. Chen, C. Liang, J. Yang, D. S. Contreras, Y. L. Clancy, E. B. Lobkovsky, O. M. Yaghi and S. Dai, Angew. Chem., Int. Ed., 2006, 45, 1390-1393; (b) C.-D. Wu and W. Lin, Angew. Chem., Int. Ed., 2007, 46, 1075-1078; (c) S. Horike, M. Dincă, K. Tamaki and J. R. Long, J. Am. Chem. Soc., 2008, 130, 5854-5855.

11 (a) H.-T. Zhang, Y.-Z. Li, T.-W. Wang, E. N. Nfor, H.-Q. Wang and X.-Z. You, Eur. J. Inorg. Chem., 2006, 35323536; (b) G. E. Kostakis, L. Casella, N. Hadjiliadis, E. Monzani, N. Kourkoumelis and J. C. Plakatouras, Chem. 
Commun., 2005, 3859-3861; (c) J. Duan, B. Zheng, J. Bai, Q. Zhang and C. Zuo, Inorg. Chim. Acta, 2010, 363, 31723177; (d) G. E. Kostakis, L. Casella, A. K. Boudalis, E. Monzani and J. C. Plakatouras, New J. Chem., 2011, 35, 1060-1071; (e) B. Wisser, A.-C. Chamayou, R. Miller, W. Scherer and C. Janiak, CrystEngComm, 2008, 10, 461464; $(f)$ R. Sun, S. Wang, H. Xing, J. Bai, Y. Li, Y. Pan and X. You, Inorg. Chem., 2007, 46, 8451-8453; $(g)$ R. Sun, Y.-Z. Li, J. Bai and Y. Pan, Cryst. Growth Des., 2007, 7, 890894; (h) C. Zuo, J. Bai, R. Sun and Y. Li, Inorg. Chim. Acta, 2012, 383, 305-311; (i) T. Min, B. Zheng, J. Bai, R. Sun, Y. Li and Z. Zhang, CrystEngComm, 2010, 12, 70-72; (j) Z. Chen, X. Liu, C. Zhang, Z. Zhang and F. Liang, Dalton Trans., 2011, 40, 1911-1918.

12 (a) F. A. Luzzio, Tetrahedron, 2001, 57, 915-945; (b) S. E. Milner, T. S. Moody and A. R. Maguire, Eur. J. Org. Chem., 2012, 3059-3067; (c) A. Majhi, S. T. Kadam and S. S. Kim, Bull. Korean Chem. Soc., 2009, 30, 1767-1770; (d) J. Boruwa, N. Gogoi, P. P. Saikia and N. C. Barua, Tetrahedron: Asymmetry, 2006, 17, 3315-3326; (e) S. Jammi, M. A. Ali, S. Sakthivel, L. Rout and T. Punniyamurthy, Chem. - Asian J., 2009, 4, 314-320; (f) C. Gan, G. Lai, Z. Zhang, Z. Wang and M. Zhou, Tetrahedron Asymmetry, 2006, 17, 725-728; (g) M. Shibasaki, M. Kanai and S. Matsunaga, Aldrichimica Acta, 2006, 39, 31-39.

13 (a) R. Ballini, G. Bosica and P. Forconi, Tetrahedron, 1996, 52, 1677-1684; (b) G. Rosini and R. Ballini, Synthesis, 1988, 833-847.

14 (a) C. Palomo, M. Oiarbide and A. Laso, Eur. J. Org. Chem., 2007, 2561-2574; (b) J. Boruwa, N. Gogoi, P. P. Saikia and N. C. Barua, Tetrahedron: Asymmetry, 2006, 24, 33153326.

15 (a) A. Bulut, A. Aslan and O. Dogan, J. Org. Chem., 2008, 73, 7373-7375; (b) M. N. Kopylovich, T. C. O. Mac Leod, K. T. Mahmudov, M. F. C. Guedes da Silva and A. J. L. Pombeiro, Dalton Trans., 2011, 40, 5352-5361; (c) S. F. Lu, D. M. Du, J. X. Xu and S. W. Zhang, J. Am. Chem. Soc., 2006, 128, 7418-7419; (d) B. M. Trost and V. S. C. Yeh, Angew. Chem., Int. Ed., 2002, 41, 861-863; (e) B. M. Trost, V. S. C. Yeh, H. Ito and N. Bremeyer, Org. Lett., 2002, 4, 2621-2623; ( $f$ ) R. Kowalczyk, L. Sidorowicz and J. Skarzewski, Tetrahedron: Asymmetry, 2007, 18, 25812586; $(g)$ Y. Kogami, T. Nakajima, T. Ikeno and T. Yamada, Synthesis, 2004, 1947-1950.

16 (a) X.-M. Lin, T.-T. Li, Y.-W. Wang, L. Zhang and C.-Y. Su, Chem. - Asian J., 2012, 7, 2796-2804; (b) J.-M. Gu, W.-S. Kim and S. Huh, Dalton Trans., 2011, 40, 1082610829; (c) L.-X. Shi and C.-D. Wu, Chem. Commun., 2011, 47, 2928-2930; (d) A. Karmakar, M. F. C. Guedes da Silva and A. J. L. Pombeiro, Dalton Trans., 2014, 43, 7795-7810.

17 A. Karmakar, C. L. Oliver, A. E. Platero-Prats, E. Laurila and L. Öhrström, CrystEngComm, 2014, 16, 8243-8251.

18 (a) K. Nakamoto, Infrared and Raman Spectra of Inorganic and Coordination Compounds, Wiley \& Sons, New York, 5th edn, 1997; (b) G. Socrates, Infrared Characteristic Group Frequencies, Wiley, New York, 1980.
19 (a) A. Nimmermark, L. Öhrström and J. Reedijk, Z. Kristallogr., 2013, 228, 311-317; (b) M. A. Halcrow, Chem. Soc. Rev., 2013, 42, 1784-1795; (c) S. Roy, P. Mitra and A. K. Patra, Inorg. Chim. Acta, 2011, 370, 247-253; (d) R. Docherty, F. Tuna, C. A. Kilner, E. J. L. McInnes and M. A. Halcrow, Chem. Commun., 2012, 48, 4055-4057; (e) K. Mack, A. W. von Leupoldt, C. Forster, M. Ezhevskaya, D. Hinderberger, K. W. Klinkhammer and K. Heinze, Inorg. Chem., 2012, 51, 7851-7858.

20 (a) R. W. Saalfrank, C. Spitzlei, A. Scheurer, H. Maid, F. W. Heinemann and F. Hampel, Chem. - Eur. J., 2008, 14, 1472-1481; (b) M. Mikuriya, R. Nukada, H. Morishita and M. Handa, Chem. Lett., 1995, 617-618; (c) R. W. Saalfrank, C. Schmidt, H. Maid, F. Hampel, W. Bauer and A. Scheurer, Angew. Chem., Int. Ed., 2006, 45, 315; (d) F. H. Allen, Acta Crystallogr., Sect. B: Struct. Sci., 2002, 58, 380; (e) A. Mukherjee, R. Raghunathan, M. K. Saha, M. Nethaji, S. Ramasesha and A. R. Chakravarty, Chem. - Eur. J., 2005, 11, 3087; $(f)$ W. Bidell, V. Shklover and H. Berke, Inorg. Chem., 1992, 31, 5561; (g) C. Mukherjee, T. Weyhermüller, E. Bothe, E. Rentschler and P. Chaudhuri, Inorg. Chem., 2007, 46, 9895-9905; (h) M. Hamid, A. A. Tahir, M. Mazhar, M. Zeller, K. C. Molloy and A. D. Hunter, Inorg. Chem., 2006, 45, 10457-10466; (i) E. A. Buvaylo, V. N. Kokozay, O. Y. Vassilyeva, B. W. Skelton, J. Jezierska, L. C. Brunel and A. Ozarowski, Inorg. Chem., 2005, 44, 206-216; (j) Z.-X. Wang, X.-L. Li, B.-L. Liu, H. Tokoro, P. Zhang, Y. Song, S. Ohkoshi, K. Hashimoto and X.-Z. You, Dalton Trans., 2008, 2103-2106.

21 (a) O. Delgado Friedrichs and M. O'Keeffe, Acta Crystallogr., Sect. A: Fundam. Crystallogr., 2003, 60, 351-360; (b) O. Delgado-Friedrichs, M. O'Keeffe and O. M. Yaghi, Phys. Chem. Chem. Phys., 2007, 9, 1035-1043.

22 (a) M. T. Johnson, Z. Džolić, M. Cetina, M. Lahtinen, M. S. G. Ahlquist, K. Rissanen, L. Öhrström and O. F. Wendt, Dalton Trans., 2013, 42, 8484-8491; (b) C.-J. Wallentin, E. Orentas, M. T. Johnson, N. B. Bathori, E. Butkus, O. F. Wendt, K. Wärnmark and L. Öhrström, CrystEngComm, 2012, 14, 178-187.

23 (a) V. J. Bulbule, G. K. Jnaneshwara, R. R. Deshmukh, H. B. Borate and V. H. Deshpande, Synth. Commun., 2001, 31, 3623-3626; (b) M. Shibasaki, M. Kanai, S. Matsunaga and N. Kumagai, Multimetallic Multifunctional Catalysts for Asymmetric Reactions: Bifunctional Molecular Catalysis, in Topics in Organometallic Chemistry, ed. T. Ikariya and M. Shibasaki, Springer-Verlag, Berlin, Heidelberg, 2011, vol. 37, pp. 1-30.

24 A. Rockenbauer and L. Korecz, Appl. Magn. Reson., 1996, 10, 29-43.

25 S. Roy, R. J. Butcher, M. S. El Fallah, J. Tercero and J. C. Pessoa, Polyhedron, 2013, 53, 269-277.

26 Z. Lu, H. Xing, R. Sun, J. Bai, B. Zheng and Y. Li, Cryst. Growth Des., 2012, 12, 1081-1084.

27 V. J. Bulbule, V. H. Deshpande, S. Velu, A. Sudalai, S. Sivasankar and V. T. Sathe, Tetrahedron, 1999, 55, 93259332. 
28 Bruker AXS Inc., Madison, Wisconsin, USA, 2004.

29 G. M. Sheldrick, University of Göttingen, Göttingen, Germany, 1996.

30 Bruker AXS Inc., Madison, Wisconsin, USA, 2003.

31 L. J. Barbour, J. Appl. Crystallogr., 1999, 351352.
32 G. M. Sheldrick, Acta Crystallogr., Sect. A: Fundam. Crystallogr., 2008, 64, 112-122.

33 G. M. Sheldrick, Acta Crystallogr., Sect. A: Fundam. Crystallogr., 2008, 64, 112-122.

34 A. L. Spek, Acta Crystallogr., Sect. D: Biol. Crystallogr., 2009, 65, 148-155. 